\title{
Effect of Hydroelutriation on Nonstructural Carbohydrates in Fibrous Roots
}

\author{
TONY SVEJCAR AND SCOTT CHRISTIANSEN
}

\begin{abstract}
Hydroelutriation can reduce the time required to remove roots from soil cores relative to conventional washing methods. However, method of washing may affect subsequent chemical analysis. We compared a hydroelutriation method to dry, hand cleaning of roots for subsequent carbohydrate content of root tissue. Fibrous roots of winter whent (Triticum aestivum L.), johnsongrass (Sorghum halepense (L.) Pers.), Caucasian bluestem (Bothriochloa caucasica (Trin.) C.E. Hubb.), and little bluestem (Schizachyrium scoparium (Michx.) Nash) were collected on 8 March and 25 May 1985. Roots were analyzed for both soluble carbohydrates and total nonstructural carbohydrates (TNC). Soluble carbohydrates were extracted using $2.5 \mathrm{mM} \mathrm{H}_{2} \mathrm{SO}_{4}$; the TNC extraction included a $24 \mathrm{~h}$ incubation with amyloglucosidase at $50^{\circ} \mathrm{C}$ in addition to weak acid hydrolysis. There were no significant differences $(P>.05)$ between cleaning procedures for any of the species on the first sampling date, and only Caucasian bluestem roots were significantly affected $(\boldsymbol{P}<.05)$ by cleaning procedure the second date. Hydroelutriation washing resulted in a $15 \%$ reduction in both soluble carbohydrates and TNC in Caucasian bluestem roots relative to dry, hand cleaning. In general, loss of nonstructural carbohydrates from washed fibrous roots was not a major concern in the 4 species we tested. However, in specific instances it may be necessary to use a correction factor to account for loss of chemical constituents when using hydroelutriation methods.
\end{abstract}

Key words: hydropneumatic elutriation, wheat, perennial grasses

Authors are research agronomists, USDA-ARS Forage and Livestock Laboratory, P.O. Box 1199, El Reno, Okla. 73036. Svejcar's present address is USDA/ARS, 920 Valley Rd., Reno NV 89512.

The authors thank .Jim Browning, Iisa Griffin, Karen Keller, Jim Trent, and Tim

Wood for assistance in sample preparation and analysis.

Manuscript accepted 1 October 1986.
In general, research on root systems has lagged behind that for aboveground plant parts (Böhm 1979). Difficulty of separating roots from soil limits feasibility of root research in many cases. However, a hydroelutriation method that speeds separation of roots from soil was described by Smucker et al. (1982), and a commercially fabricated unit is currently available. Smucker et al. estimated that 2 people could process 72 soil cores $(200$ to $800 \mathrm{cc}$ of soil volume) per hour with the hydroelutriation system, as oppposed to 12 soil cores per hour with hand washing. Each soil core may require up to 18 liters of water, and thus the potential for leaching of soluble components out of roots appeared to exist. The objective of this study was to determine how hydroelutriation compared with hand cleaning in subsequent analysis of soluble and total nonstructural carbohydrate (TNC).

\section{Materials and Methods}

The study was conducted at the USDA-ARS Forage and Livestock Research Laboratory, $4 \mathrm{~km}$ west of El Reno, Okla. Soils on study sites were silt loams of either the Norge series (Udic Paleustolls) or the Dale series (Pachic Haplustolls). Fibrous roots of Caucasian bluestem (Bothriochloa caucasica (Trin.) C.E. Hubb.), little bluestem (Schizachrium scoparium (Michx.) Nash), johnsongrass (Sorghum halepense (L.) Pers.), and winter wheat (Triticum aestivum L. 'TAM 101') were collected on 8 March and 25 May 1985. Samples of each species were selected at random from 8 different locations in a field. Roots were excavated to a depth of 15 
Table 1. Percent soluble and total nonstructural carbohydrates of fibrous roots which had been washed with a hydroelutriation system (W) or cleaned by hand (N).

\begin{tabular}{|c|c|c|c|c|c|c|c|c|}
\hline \multirow[b]{3}{*}{ Species } & \multicolumn{4}{|c|}{8 March } & \multicolumn{4}{|c|}{$25 \mathrm{May}$} \\
\hline & \multicolumn{2}{|c|}{ Soluble } & \multicolumn{2}{|c|}{ Total } & \multicolumn{2}{|c|}{ Soluble } & \multicolumn{2}{|c|}{ Total } \\
\hline & $\mathbf{N}$ & $\mathbf{W}$ & $\mathbf{N}$ & $\mathbf{w}$ & $\mathbf{N}$ & W & $\mathbf{N}$ & W \\
\hline $\begin{array}{l}\text { Caucasian bluestem } \\
\text { Little bluestem } \\
\text { Johnsongrass } \\
\text { Wheat }\end{array}$ & $\begin{array}{l}7.7 \pm 0.61 \\
4.9 \pm 1.1 \\
1.7 \pm 1.0 \\
3.0 \pm 1.1\end{array}$ & $\begin{array}{l}7.9 \pm 1.0 \\
5.0 \pm 1.0 \\
1.8 \pm 1.1 \\
2.8 \pm 0.7\end{array}$ & $\begin{array}{r}8.0 \pm 1.1 \\
12.9 \pm 2.9 \\
1.9 \pm 0.7 \\
3.0 \pm 1.0\end{array}$ & $\begin{array}{r}8.3 \pm 1.3 \\
12.7 \pm 1.9 \\
2.1 \pm 0.5 \\
2.9 \pm 0.7\end{array}$ & $\begin{array}{l}3.9 \pm 0.5^{*} \\
3.0 \pm 0.2 \\
3.4 \pm 1.1 \\
0.3 \pm 0.3\end{array}$ & $\begin{array}{l}3.2 \pm 0.8 \\
2.8 \pm 0.3 \\
3.1 \pm 1.2 \\
0.4 \pm 0.4\end{array}$ & $\begin{array}{l}4.8 \pm 0.4^{*} \\
3.8 \pm 0.3 \\
5.9 \pm 0.8 \\
1.7 \pm 0.2\end{array}$ & $\begin{array}{l}4.1 \pm 1.0 \\
3.6 \pm 0.3 \\
5.3 \pm 1.2 \\
1.5 \pm 0.8\end{array}$ \\
\hline
\end{tabular}

IMean \pm standard deviation $(n=8)$

* Method of cleaning had a significant effect $(p<.05)$.

$\mathrm{cm}$ with a shovel, thus no specific volume of soil was collected. In all cases we collected roots attached to shoots to ensure proper species identification. Each sample was divided and a subsample washed for 8 minutes in a hydroelutriation system (Gillison's Inc., Benzonia, Mich.) ${ }^{1}$. Remaining subsamples were handled as follows: soil and roots were spread on a tray and roots removed with tweezers. Clay content of the soil was such that wet soil could not be easily removed with brushes so roots were placed in a microwave for $30 \mathrm{~s}$ to dry remaining soil, which could then be removed from roots with fine brushes. Water was not used during any phase of manual cleaning to ensure no leaching of soluble components occurred. All subsamples were placed in a forced-air oven at $50^{\circ} \mathrm{C}$ for $24 \mathrm{~h}$ and ground to pass through a $1-\mathrm{mm}$ screen in a Udy cyclone mill (Udy Corporation, Ft. Collins, Colo.).

Extraction of soluble carbohydrates and TNC was accomplished by placing $100 \mathrm{mg}$ of root sample in a $25-\mathrm{ml}$ erlenmeyer flask, to which $10 \mathrm{ml}$ of $2.5 \mathrm{mM} \mathrm{H}_{2} \mathrm{SO}_{4}$ was added. Glucose standard solutions were prepared by diluting stock solutions to $200,400,600,800,1,000,1,200$, and $1,400 \mathrm{mg} / 1$ with $2.5 \mathrm{mM}$ $\mathrm{H}_{2} \mathrm{SO}_{4}$ and placing $10 \mathrm{ml}$ of each standard in an erlenmeyer flask without sample. Flasks were immersed in boiling water for $50 \mathrm{~min}$, cooled in an ice bath, and $9 \mathrm{ml}$ of $0.2 \mathrm{M}$ acetate buffer ( $\mathrm{pH}$ 4.4) was added to both standards and samples. All solutions were thoroughly mixed before a 2-ml aliquot was pipetted from samples and standards for determination of soluble carbohydrates. These aliquots were centrifuged, decanted into autosampling cuvettes, and held in the refrigerator. One milliliter of $0.5 \%$ amyloglucosidase was added to remaining samples and standards in erlenmeyer flasks before they were placed in a water bath $\left(50^{\circ} \mathrm{C}\right)$ for a $24-\mathrm{h}$ incubation period. Samples and standards were centrifuged and supernatants placed in autosampling cuvettes for determination of TNC.

All analyses were conducted with a flow-injection analyzer (Quickchem System IV, Model 170, Lachat Chemicals Inc., Mequon, Wis.). The flow-injector consisted of an automatic sampler, a reagent manifold and proportioning pump to control mixing of reagents and flow rates respectively, and a colorimeter (which measured absorbance at $410 \mathrm{~nm}$ ) interfaced to a programmer/printer. We used the colorimetric reaction between p-hydroxybenzoic acid hydrazide and the hydrolyzed reducing sugars to measure soluble carbohydrates and TNC from $45 \mu 1$ volumes of samples and standards. A detailed account of the procedure, including reagent concentrations, tubing sizes, flow rates, and programmed input parameters is presented in Trent and Christiansen (1986). Results were analyzed using paired- $t$ comparisons for washing procedure by species, date, and carbohydrate component.

\section{Results and Discussion}

The 8 March sampling was nearly a month prior to initiation of aboveground growth for the warm-season species (Caucasian bluestem, little bluestem, and johnsongrass), whereas winter wheat was actively growing. Initiation of root growth of perennial grass is generally associated with aboveground growth (Ares 1976, Caldwell et al. 1981), thus it is unlikely that the warm-season species in our study had initiated root growth by 8 March. On the other hand, Gregory et al. (1978) found that winter wheat maintained active root growth until anthesis, which occurred at least a month after the 8 March sampling. There were no significant $(P>.05)$ effects of washing method on soluble carbohydrates or TNC for any of the species on 8 March (Table 1). Late May is a period of active growth for the warm-season grasses and grain-filling in winter wheat. Root carbohydrate content of the 2 bunchgrasses (Caucasian bluestem and little bluestem) declined between early March and late May, presumably because carbohydrate was used to support root growth. There was a significant effect $(P<.05)$ of washing procedure of Caucasian bluestem, with hydroelutriation resulting in a $15 \%$ reduction in soluble carbohydrate and TNC. The difference between methods for little bluestem was not significant $(P>.05)$. Without more extensive information on rooting habits and root anatomy, it is difficult to say why one species and not another was affected by hydroelutriation. The carbohydrate trend over time was opposite in johnsongrass relative to the bunchgrasses. The increase in carbohydrate level of johnsongrass roots between early March and late May occurred during a time when the thick rhizomes to which roots were attached declined from 50 to $60 \%$ TNC to 30 to $40 \%$ TNC (unpublished data). Thus, export of carbohydrate from rhizomes to fibrous roots may account for the increase. In spite of the fact that roots were actively growing and carbohydrate levels increasing, the difference between root washing procedures was not significant $(P>.05)$. Carbohydrate levels were very low in winter wheat in late May, probably because of the mobilization of reserves for grain-filling (Austin et al. 1977). Again, there were no signifiant effects $(P>.05)$ of washing procedure on carbohydrate content.

Loss of root carbohydrate resulting from hydroelutriation of soil cores can probably be accounted for in 2 ways: (1) carbohydrate is leached from roots, or (2) root tips and newly formed roots (which are higher in carbohydrate content than suberized roots) are preferentially lost during the washing process. In the case of Caucasian bluestem on the second sampling, all of the loss in TNC can be accounted for by reduction of soluble carbohydrate; thus leaching would appear to be the primary cause of lowered TNC content. The hydroelutriation system recovers a high percentage (>95\%) of washed roots (Smucker et al. 1982); however, we are not aware of any information concerning the nature of roots which are lost during washing. Root anatomy and growth phase will probably affect potential leaching of carbohydrate and loss of fine roots; however, in the 4 species we studied, the difference in carbohydrate content between hand cleaning and hydroelutriation was at most $15 \%$. For root systems subject to loss of carbohydrate a correction factor may be in order when roots washed with a hydroelutriation are used for carbohydrate analysis. 


\section{Literature Cited}

Ares, J. 1976. Dynamics of the root system of blue grama. J. Range Manage. 29:208-213.

Austin, R.B., J.A. Edrich, M.A. Ford, and R.D. Blackwell. 1977. The fate of dry matter, carbohydrates and ${ }^{14} \mathrm{C}$ lost from the leaves and stems of wheat during grain filling. Ann. Bot. 41:1309-1321.

Böhm, W. 1979. Methods of studying root systems. Springer-Verlag, New York.

Caldwell, M.M., J.H. Richards, D.A. Johnson, R.S. Nowak, and R.S. Dzurec. 1981. Coping with herbivory: photosynthetic capacity and resource allocation in 2 semiarid Agropyron bunchgrasses. Oecologia 50:14-24.
Gregory, P.J., M. McGowan, P.V. Biscoe, and B. Hunter. 1978. Water relations of winter wheat. 1. Growth of root system. J. Agr. Sci. 91:91-102.

Smucker, A.J.M., S.L. McBurney, and A.K. Srivastave. 1982. Quantitative separation of roots from compacted soil profiles by the hydropneumatic elutriation system. Agron. J. 74:500-503.

Trem, J.D., and S. Christiansen. 1986. Determination of total nonstructural carbohydrates in forage tissue by p-hydroxybenzoic acid hydrazide flow-injection analysis. J. Agr. Food Chem. 34:1033-1037. 